\title{
An 8 week open-label interventional multicenter study to explore the lung clearance index as endpoint for clinical trials in cystic fibrosis patients $\geq 8$ years of age, chronically infected with Pseudomonas aeruginosa
}

\author{
Sivagurunathan Sutharsan ${ }^{1 *}$ (D, Susanne Naehrig ${ }^{2}$, Uwe Mellies ${ }^{3}$, Christian Sieder $^{4}$ and Jörg Ziegler ${ }^{4}$
}

\begin{abstract}
Background: Forced expiratory volume in 1 second $\left(F E V_{1}\right)$ is the only parameter currently recognized as a surrogate endpoint in cystic fibrosis (CF) trials. However, $\mathrm{FEV}_{1}$ is relatively insensitive to changes in the small airways of patients with milder lung disease. This pilot study aimed to explore the lung clearance index $(\mathrm{LCl})$ as a marker for use in efficacy trials with inhaled antibiotics in CF.

Methods: This open-label, single-arm study enrolled CF patients with Pseudomonas aeruginosa infection, who were treated with tobramycin (28-day on/off regime). $\mathrm{FEV}_{1}, \mathrm{LCl}$ and bacterial load in sputum (CFU) were assessed at baseline, after 1, 4 and 8 weeks of treatment.

Results: All patients $(n=17)$ showed elevated $\mathrm{LCl}$ of $>11$ despite 3 patients having normal $\mathrm{FEV}_{1}(>90 \%$ predicted) at baseline. Overall, $\mathrm{LCl}$ improved in 8 (47\%) patients and $\mathrm{FEV}_{1}$ in 9 (53\%) patients. At week 4, LCl improved by 0.88 , $\mathrm{FEV}_{1}$ increased by $0.52 \%$, and $P$. aeruginosa reduced by $30,481.3 \mathrm{CFU} / \mathrm{mL}$. These changes were however statistically non-significant. Six adverse events occurred in 5/17 (29.4\%) patients, most of which were mild-to-moderate in severity.
\end{abstract}

Conclusions: Due to the low evaluable sample size, no specific trend was observed related to the changes between $\mathrm{LCl}, \mathrm{FEV}_{1}$ and $\mathrm{CFU}$. Based on the individual data from this study and from recently published literature, $\mathrm{LCl}$ has been shown to be a more sensitive parameter than $\mathrm{FEV}_{1}$ for lung function. $\mathrm{LCl}$ can be hypothesized to be an appropriate endpoint for efficacy trials in CF patients if the heterogeneity in lung function is limited by enrolling younger patients or patients with more milder lung disease and thus, limiting the ventilation inhomogeneities.

Trial registration: The study is registered with ClinicalTrials.gov, identifier: NCT02248922.

Keywords: Cystic fibrosis, Forced expiratory volume in 1 second, Lung clearance index, Tobramycin, Pseudomonas aeruginosa, Antibiotics, Clinical trials

\footnotetext{
* Correspondence: sivagurunathan.sutharsan@rlk.uk-essen.de

'Division for Cystic Fibrosis, Department of Pulmonary Medicine, University Medicine Essen - Ruhrlandklinik, Essen, Germany

Full list of author information is available at the end of the article
}

(c) The Author(s). 2020 Open Access This article is licensed under a Creative Commons Attribution 4.0 International License, which permits use, sharing, adaptation, distribution and reproduction in any medium or format, as long as you give appropriate credit to the original author(s) and the source, provide a link to the Creative Commons licence, and indicate if changes were made. The images or other third party material in this article are included in the article's Creative Commons licence, unless indicated otherwise in a credit line to the material. If material is not included in the article's Creative Commons licence and your intended use is not permitted by statutory regulation or exceeds the permitted use, you will need to obtain permission directly from the copyright holder. To view a copy of this licence, visit http://creativecommons.org/licenses/by/4.0/. The Creative Commons Public Domain Dedication waiver (http://creativecommons.org/publicdomain/zero/1.0/) applies to the data made available in this article, unless otherwise stated in a credit line to the data. 


\section{Background}

Cystic fibrosis (CF) is a life-limiting, autosomal recessive genetic disease [1], characterized by a reduced quantity and/or function of the cystic fibrosis transmembrane conductance regulator (CFTR) protein, leading to an impaired mucociliary clearance of the airways, followed by chronic inflammation, infection and thus progressive and irreversible loss of lung function [2]. The main driver of lung function decline beyond infancy in people with CF is the chronic infection with Pseudomonas aeruginosa [3]. Although it is a complex multiorgan and multifactorial disease, the chronic lung infection by $P$. aeruginosa is the primary cause of morbidity. Therefore, an antibiotic maintenance therapy is the preferred standard treatment in these patients [2]. Inhaled tobramycin typically given in 28 daycycles of 1 month on and 1 month off periods, is recommended for treating individuals with CF aged $\geq 6$ years, who have mild to moderate lung disease with persistent $P$. aeruginosa infection [4].

Currently, forced expiratory volume in 1 second $\left(F E V_{1}\right)$ and rate of $\mathrm{FEV}_{1}$ decline are the only accepted surrogate markers for assessing lung function decline [5]. However, with significant advances in the care of patients with CF, such as the newly introduced CFTRtargeted therapies and considerable improvement in survival rates, the rate of decline in $\mathrm{FEV}_{1}$ has slowed $[6,7]$, leading to a preservation of spirometric lung function within the normal range into young adulthood [8, 9]. Moreover, $\mathrm{FEV}_{1}$ is insensitive during early stages of lung disease resulting in normal spirometry findings, despite the progression of structural damage in lungs, for example in bronchiectasis. Therefore, the reliability on $\mathrm{FEV}_{1}$ as an indicator of disease progression especially in the early stages of lung disease has become questionable $[9,10]$. Increasing evidence suggest that in patients with $\mathrm{CF}$, pulmonary deterioration starts early in life and can occur in the absence of respiratory symptoms at normal lung function in terms of $\mathrm{FEV}_{1}$ [11]. Thus, there is a need for early intervention before onset of irreversible lung damage based on alternative clinically sensitive surrogate markers for detection of early CF lung disease [12].

A multiple breath washout (MBW) test assessing ventilation inhomogeneity has been shown to be a sensitive lung function test to detect early pathology in patients with CF [12]. The most commonly reported MBW outcome is the lung clearance index (LCI), which is a robust, noninvasive technique to detect early lung disease changes across all age groups [13, 14]. Consequently, LCI has been evaluated as a new sensitive surrogate endpoint for measuring trial outcomes focusing on the early stages of disease [13]. LCI was used for the first time as the primary study endpoint in a pivotal trial in children (6-11 years) with CF treated with an oral combination of CFTR modulators, lumacaftor (LUM) and ivacaftor
(IVA). Treatment with LUM/IVA, demonstrated a statistically significant improvement in lung function, as measured by $\mathrm{LCI}_{2.5}$ and percent predicted $\mathrm{FEV}_{\mathrm{I}}\left(\mathrm{ppFEV} \mathrm{V}_{1}\right)$, versus placebo in children with $\mathrm{CF}$ homozygous for F508del-CFTR [15]. However, there is still very limited data available on the use of LCI as a clinical endpoint for CF patients treated with inhaled antibiotics. Recent evidence from longitudinal studies also suggest a between-visit variability in the LCI with increasing severity of the lung disease [16].

The aim of the present study was to explore the clinical utility of LCI for assessing short-term clinical response to inhaled tobramycin antibiotic therapy in patients with CF positive for $P$. aeruginosa, aged 6 years and older with mild to moderate lung disease.

\section{Methods}

\section{Study design and patients}

This was an open-label, single arm study in CF patients with chronic $P$. aeruginosa infection. The study consisted of screening period (5 to 26 days) to test the presence of $P$. aeruginosa (Visit 1), a baseline visit (Visit 2), a visit 1 week after baseline visit (Visit 3), followed by a visit after 28 days on-treatment period (Visit 4) and subsequently a visit after 28 days off-treatment period (Visit 5 , end of study). All patients were treated with tobramycin monotherapy, either as an inhalation solution (TIS) $300 \mathrm{mg}$ twice daily (BID) or as an inhalation pow-

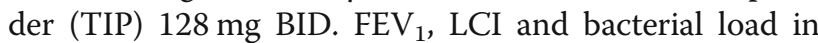
sputum (colony forming units [CFU]) were assessed at baseline, after 1, 4 and 8 weeks of treatment. Spirometric and LCI assessments were conducted before or at least 1 hour after the inhalation of the drug. MBW measurements to assess the LCI were performed with the ExhalyzerD (Eco Physics GmbH, Munich, Germany). The study design was approved by the independent ethics committee and institutional review boards; and was in accordance with the Declaration of Helsinki.

The study enrolled patients from seven sites in Germany, diagnosed with CF aged 6 to 50 years, with a chronic infection of airways with $P$. aeruginosa within the last 12 months and at screening. Patients with an elevated LCI of $\geq 7.5$ [17] and $\mathrm{FEV}_{1}$ of $\geq 50 \%$ at screening, and those receiving inhaled tobramycin monotherapy in 28 days on/off regime in the past 3 month before screening were included. Informed consent was obtained from patients for having their data collected. Patients receiving more than one class of inhaled antipseudomonal antibiotic during the study or in the past 56 days prior to the baseline visit, or who used oral or intravenous antipseudomonal antibiotics within 28 days prior to the onphase of the study drug or loop diuretics within 7 days prior to the first study medication administration, were excluded. 


\section{Study assessments}

The primary endpoint was change in LCI after 4 weeks of treatment versus baseline. Secondary endpoints included change in $\mathrm{FEV}_{1}$ and CFU after week 4 following treatment; change of LCI after week 1 following treatment; change of LCI, FEV 1 and CFU between week 4 (end of the study drug inhalation in the current treatment cycle) and week 8 (prior to the start of the study drug inhalation in the following treatment cycle); and correlation between the changes of LCI, FEV 1 and CFU after weeks 1, 4 and 8 versus baseline, respectively.

For LCI assessment, the multiple breath washout device Exhalyzer D (Ecomedics, Zurich, Switzerland) was used, with Nitrogen as the tracer gas. All equipment and the device software were identical throughout the sites. LCI was determined according to the Exhalyzer D MBW SOP of the manufacturer that is based on the current MBW guidelines of the European Cystic Fibrosis Society (ECFS), and all study sites were provided with a device specific training before start of the study.

The mean of two acceptable MBW measurements was used for analysis if the coefficient of variation (CV) for LCI was $\leq 5 \%$, else another MBW measurement was performed (functional residual capacity [FRC] not $>25 \%$ ). The mean of three acceptable MBW measurements was used, if the CV for LCI was $\leq 10 \%$ (FRC not $>25 \%$ ). One more MBW measurement was to be performed otherwise. MBW was repeated four times, and the mean of two measurements with the smallest difference in LCI was used. Single MBW assessments were stopped immediately if more than one cough event occurred during the wash-out phase, if there was a continuous decrease of the carbon dioxide concentration for $>60 \mathrm{~s}$, and if there was a change in the breathing pattern of more than $20 \%$. For the measurements used to calculate the mean value, a quality control was done by a central assessor (MBW specialist of the manufacturer).

\section{Statistical analysis}

Assuming a change of $5 \%$ in $\mathrm{FEV}_{1}$ with an intraindividual standard deviation of $9 \%$ between the on- and offtreatment cycles, 28 patients would provide $80 \%$ power on a 2 -sided $5 \%$ significance level to detect this change. To compensate for protocol deviations and dropouts, 35 patients were planned to be recruited into this trial. All variables were summarized using descriptive statistics. Analyses were performed by using SAS Version 9.4.

Changes in LCI from baseline were analyzed using an analysis of variance (ANOVA) model. Estimates over time were presented as least squares (LS)-means, pairwise LS-mean differences along with 95\% confidence intervals (CI) and 2-sided p-values for the pairwise differences between visits. If the baseline value was missing, then change was calculated from the data recorded at the screening. The primary analysis included patients with a valid observation at the baseline and postbaseline visits.

\section{Results}

In total, 17 patients ( 5 patients treated with TIS and 12 patients with TIP) were enrolled and completed the study. The majority of the patients (14 patients, $82.4 \%$ ) were aged $>17$ years, with an overall mean age of $26.4 \pm$ 9.99 years and body mass index (BMI) of $21.1 \pm 2.46 \mathrm{~kg} /$ $\mathrm{m}^{2}$. The study had a higher proportion of men $(64.7 \%)$ versus women (35.3\%). All patients provided valid MBW measurements with three trials each, at each visit, and had complete data on LCI and $\mathrm{FEV}_{1}$. Not all patients were able to expectorate sputum and thus, complete CFU data were only available for 10 patients. At baseline, mean LCI was $17.99 \pm 4.73$ (95\% CI: 11.16-29.14) and $\mathrm{FEV}_{1}$ was $76.96 \pm 18.60 \%$ predicted (95\% CI: $44.66-$ 115.5) (Fig. 1a). All patients demonstrated considerably elevated LCI of $>11$ (normal range 6.5-7.5) despite 3 patients having a normal lung function $\left(\mathrm{FEV}_{1}>90 \%\right.$ predicted) at baseline. The demographics and characteristics of patients at the baseline are presented in Table $\mathbf{1}$.

The mean LCI improved slightly over time from baseline. At week 4, LCI improved by 0.88 (17.10 $\pm 0.84 ; 95 \%$ CI: 15.31-18.88) from baseline, which was statistically non-significant $(p=0.41)$. Overall, 8 (47\%) patients showed an improved LCI at week 4 from baseline. At least 3 patients showed worsening of LCI despite improvement in $\mathrm{FEV}_{1}$ (Table 2).

The mean $\mathrm{FEV}_{1}$ increased by $0.52 \%$ (77.48 \pm 20.56 ; 95\% CI: 66.91-88.05) at week 4 from baseline, which was not statistically significant $(\mathrm{p}=0.70)$. At week 4,9 patients (53\%) showed an improved $\mathrm{FEV}_{1}$ and $P$. aeruginosa reduced by $30,481.3 \mathrm{CFU} / \mathrm{mL}(26,113.0 \mathrm{CFU} / \mathrm{mL}$; 95\% CI: $(-32,035.02-84,261.05)$ as compared to baseline $(56,594.3)$. However, the change in CFU was not statistically significant $(\mathrm{p}=0.35)$. The mean LCI improved slightly $(-0.479)$ after 1 week of drug inhalation $(p=0.59)$. The changes in LCI $(p=0.42), \operatorname{FEV}_{\mathrm{I}}(p=$ $0.39)$, and CFU $(p=0.35)$ from week 4 to week 8 were statistically non-significant (Fig. 1b-d). A statistically significant positive correlation was observed between LCI and CFU at week $1(r=0.59, p=0.0321)$ and week $4(\mathrm{r}=0.79, \mathrm{p}=0.0046)$ from baseline. A negative correlation $(r=-0.64)$ was seen between $\mathrm{FEV}_{1}$ and CFU at week 4 from baseline, which was statistically significant $(\mathrm{p}=0.0462)$.

Overall, 6 adverse events (AEs) occurred in 5/17 patients $(29.4 \%)$ (3 patients on TIP and 2 patients on TIS), most of which were related to respiratory, thoracic and mediastinal disorders $(n=3,17.6 \%)$. Most of these were mild or moderate in severity (Table 3 ). 


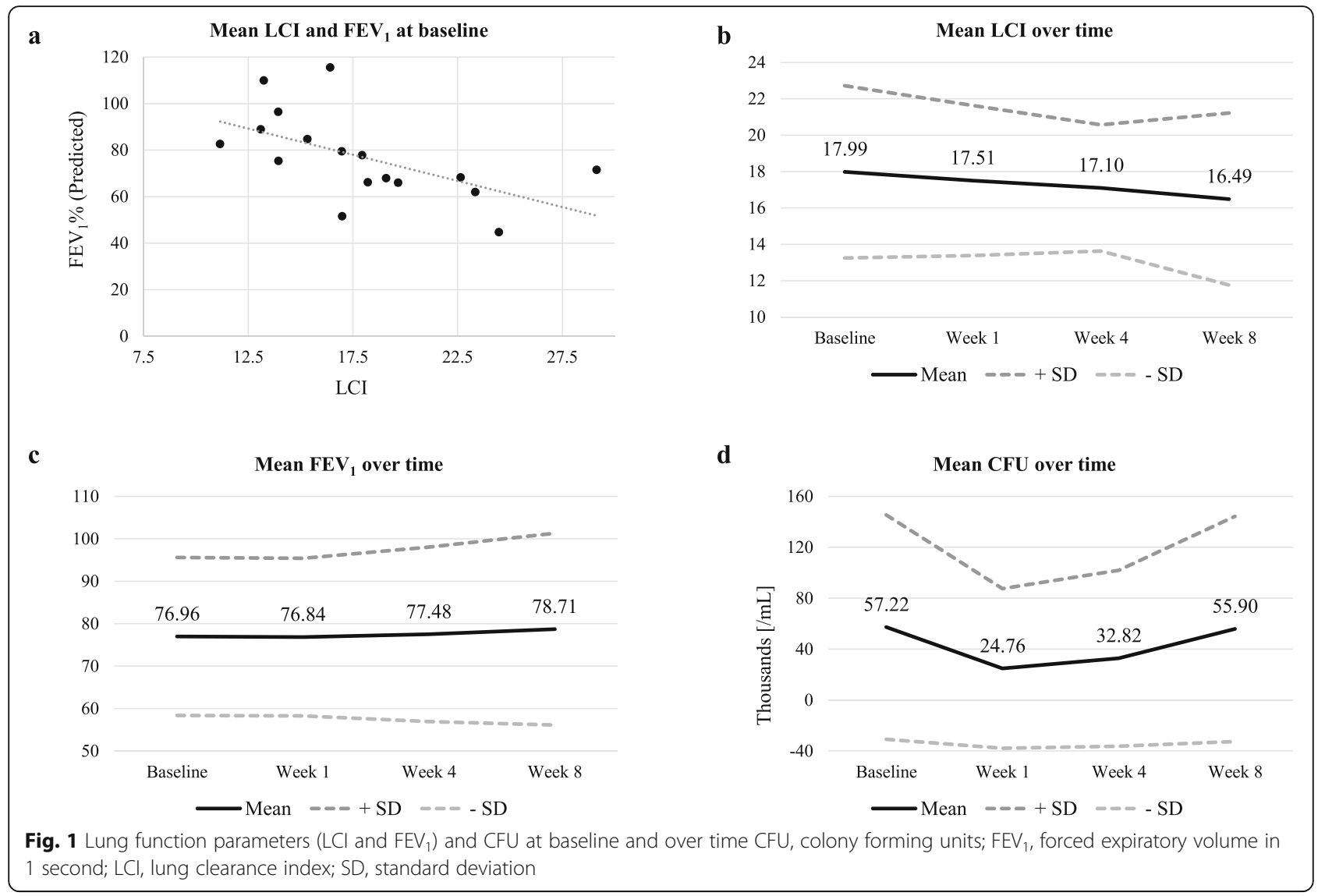

\section{Discussion}

It has been shown that lung damage induced by inflammation precedes $\mathrm{FEV}_{1}$ decline [10]. LCI derived from MBW reflects ventilation defects in the respiratory tract, including the early dysfunction in small airways, which are not easily identified with traditional spirometry methods [13]. Therefore, the present study assessed the clinical utility of LCI for assessing the response to inhaled tobramycin antibiotic therapy (both nebulized and powder inhalers) in patients with $\mathrm{CF}$

Table 1 Patient demographics and baseline characteristics ( $N=17)$

\begin{tabular}{|c|c|}
\hline Variable & \\
\hline Age, years & $26.4(9.99)$ \\
\hline Men, n (\%) & $11(64.7)$ \\
\hline Height, cm & $171.12(12.8)$ \\
\hline Weight, kg & $62.6(12.9)$ \\
\hline Waist circumference, $\mathrm{cm}$ & $85.1(22.6)$ \\
\hline $\mathrm{BMI}, \mathrm{kg} / \mathrm{m}^{2}$ & $21.1(2.5)$ \\
\hline $\mathrm{LCl}$ & $17.99(4.7)$ \\
\hline $\mathrm{FEV}_{1}(\%)$ & $76.96(18.6)$ \\
\hline
\end{tabular}

Data are expressed as mean (SD) unless indicated otherwise $B M I$ body mass index, $F E V$ forced expiratory volume in 1 second, $L C l$ lung clearance index, SD standard deviation positive for $P$. aeruginosa. The use of both nebulized and powder inhalers in this study was based on evidence from previous non-inferiority studies suggesting similar efficacy between the two aerosol therapies [18]. In the present study, three patients had a significantly elevated LCI despite having a normal $\mathrm{FEV}_{1} \%$ at baseline. In addition, relative changes in LCI at week 4 versus baseline for individual patients were higher than the respective $\mathrm{FEV}_{1}$ differences (Table 2 and Fig. 2), indicating a higher sensitivity of lung function assessment with MBW compared to classical spirometry. Similar findings from previously published data also showed that LCI provides a more sensitive overall estimate of ventilation inhomogeneity compared to $\mathrm{FEV}_{1}$, at least in patients with mild lung disease [19].

There is increasing evidence on the clinical utility of LCI. In addition to LCI being used as a clinical endpoint $[5,15]$, it has also been used to assess mucociliary clearance in young children [20] treated with CFTRmodulators [15] and to monitor disease progression [21], or both [22]. However, this study with inhaled tobramycin demonstrated that changes in LCI, FEV ${ }_{1}$ and CFU at week 1,4 and 8 were not statistically significant. There was no specific trend observed with respect to correlation between the changes of $\mathrm{LCI}, \mathrm{FEV}_{1}$ and CFU 
Table 2 Lung function parameters after visit 4 versus baseline

\begin{tabular}{|c|c|c|c|c|c|}
\hline Patient \# & Age & FEV 1 at baseline (\% predicted) & $\mathrm{dLCl}$ in \% of baseline & $\mathrm{dFEV}_{\mathbf{1}}$ in $\%$ of baseline & $\mathrm{dCFU}[/ \mathrm{g}]$ \\
\hline 1 & 17 & 82.6 & $29.8 \%$ & $11.0 \%$ & $-17,120$ \\
\hline 2 & 17 & 84.7 & $3.8 \%$ & $10.6 \%$ & - \\
\hline 3 & 37 & 71.5 & $-42.4 \%$ & $7.2 \%$ & $-224,700$ \\
\hline 4 & 19 & 68.2 & $-24.6 \%$ & $7.0 \%$ & - \\
\hline 5 & 19 & 115.5 & $-19.8 \%$ & $4.4 \%$ & - \\
\hline 6 & 24 & 109.9 & $10,5 \%$ & $2.7 \%$ & $-12,200$ \\
\hline 7 & 35 & 77.8 & $-3.0 \%$ & $2.1 \%$ & $-12,640$ \\
\hline 8 & 37 & 79,5 & $6.7 \%$ & $0.9 \%$ & -40 \\
\hline 9 & 22 & 44.7 & $-24.1 \%$ & $0.6 \%$ & 20,800 \\
\hline 10 & 18 & 65.9 & $-4.8 \%$ & $0.0 \%$ & $-225,600$ \\
\hline 11 & 41 & 61.9 & $-4.6 \%$ & $0.0 \%$ & -8800 \\
\hline 12 & 30 & 51.5 & $-15.6 \%$ & $-1.0 \%$ & 100 \\
\hline 13 & 8 & 88.9 & $-6.9 \%$ & $-2.2 \%$ & 732 \\
\hline 14 & 43 & $101.1 \%$ & $8.7 \%$ & $-5.1 \%$ & 14,000 \\
\hline 15 & 34 & $67.9 \%$ & $17.1 \%$ & $-6.9 \%$ & $-10,040$ \\
\hline 16 & 23 & $75.3 \%$ & $4.8 \%$ & $-12.5 \%$ & 29,600 \\
\hline 17 & 24 & $68.6 \%$ & $36.2 \%$ & $-13.0 \%$ & - \\
\hline
\end{tabular}

CFU colony forming units, $d$ difference at week 4 versus baseline, $F E V_{1}$ forced expiratory volume in one second, $L C l$ lung clearance index

after week 1,4 and 8 versus baseline. This may be attributed to the heterogeneity in LCI response to antibiotic treatment seen in the individual data for MBW and spirometry shown in Fig. 2. These results are in line with previously published studies [23, 24] and pooled analyses [25]. Despite the use of a more efficient therapy (inhaled formulation) in terms of an increased bioavailability of tobramycin in sputum we observed heterogeneity in the present study which is comparable to the findings seen with intravenous antibiotic treatment in children with CF [23]. In contrast to the outcome from the present study, a short-term study (1 month) with $32 \mathrm{CF}$ children on intravenous antibiotic treatment showed a significant improvement in LCI compared with $\mathrm{FEV}_{1}$ [26].
However, data about LCI as outcome measure for shortterm efficacy of antibiotics in CF remains very limited.

The observed heterogeneity in lung function response to therapy can partly be attributed to the nonresponders, which could be due to a few patients becoming refractory to inhaled antibiotics [27]. Further, there were single cases of negative, or positive change in CFU in some patients however, such findings are not conclusive, also because not all patients were able to expectorate sputum and thus, CFU data was missing for some patients. In addition, CFU assessment in general is characterized by huge intraindividual variation and therefore, any non-significant findings have to be evaluated with caution. Based on this data, one may speculate that

Table 3 Adverse event

\begin{tabular}{llll}
\hline System organ class & TIS $(\boldsymbol{N}=5), \boldsymbol{n}(\%)$ & TIP $(\mathrm{N}=12), \boldsymbol{n}(\%)$ & Overall $(\boldsymbol{N}=17), \boldsymbol{n}(\%)$ \\
\hline Any MedDRA system organ class & $2(40.0)$ & $3(25.0)$ & $5(29.4)$ \\
Injury, poisoning and procedural complications & $1(20.0)$ & $0(0.0)$ & $1(5.9)$ \\
Sunburn & $1(20.0)$ & $0(0.0)$ & $1(5.9)$ \\
Investigations & $1(8.3)$ & $0(0.0)$ & $1(5.9)$ \\
Forced expiratory volume decreased & $1(8.3)$ & $1(20.0)$ & $3(17.6)$ \\
Respiratory, thoracic and mediastinal disorders & $2(16.7)$ & $0(0.0)$ & $1(5.9)$ \\
Cough & $1(8.3)$ & $1(20.0)$ & $1(5.9)$ \\
Haemoptysis & $0(0.0)$ & $0(0.0)$ & $1(5.9)$
\end{tabular}

TIS Tobramycin inhalation solution, TIP Tobramycin inhalation powder. Percentages are based on $\mathrm{N}$ of each group in safety set. A patient with multiple occurrences of an AE is counted only once in the AE category. A patient with multiple adverse events within a primary system organ class is counted only once in each system organ class total row. MedDRA version 20.0 has been used for coding of adverse events 


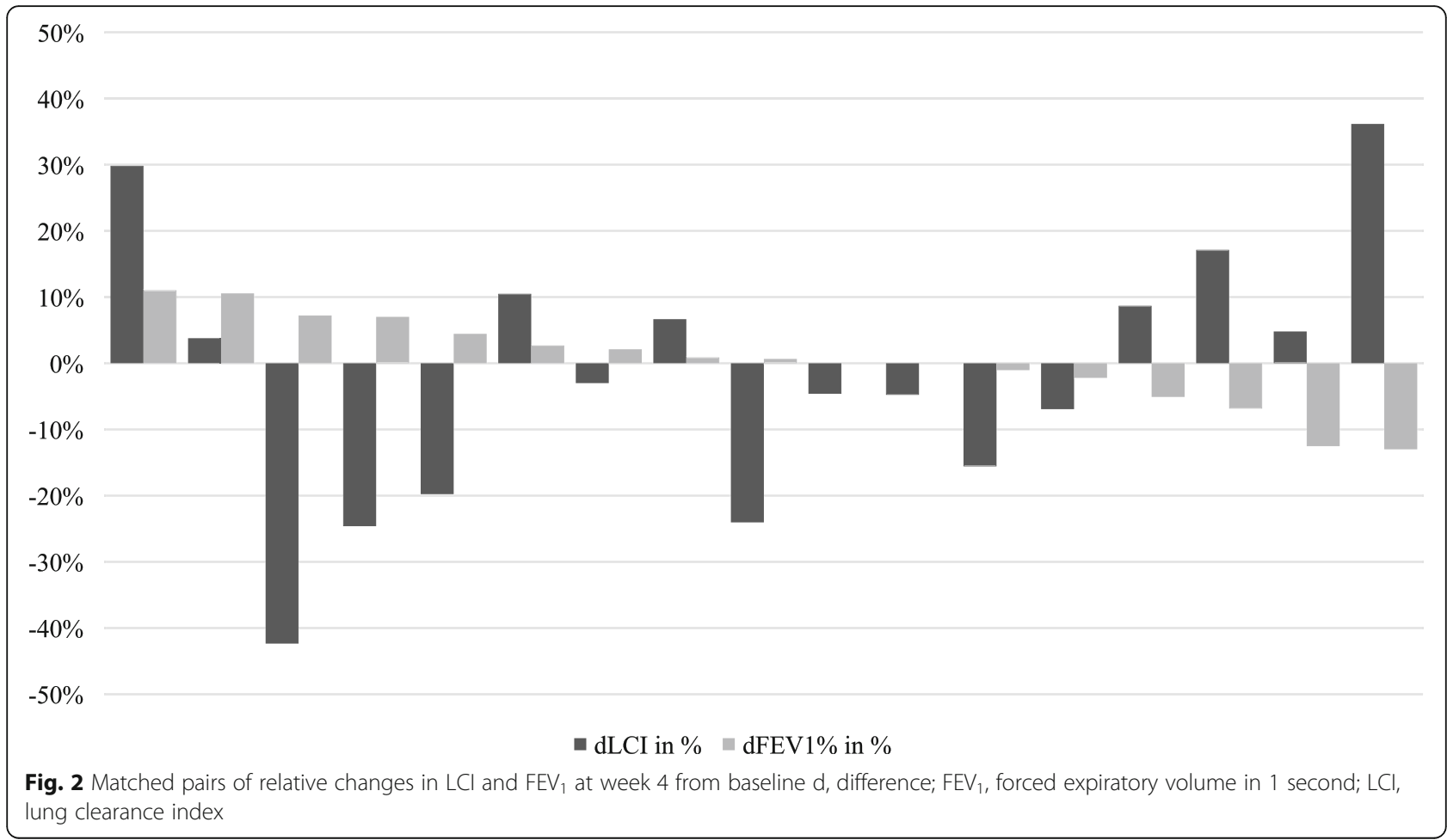

therapy response in these patients with mild to moderate lung disease, chronically treated with inhaled tobramycin was weak and/or heterogeneous. At least 3 patients showed worsening of LCI despite an improvement in $\mathrm{FEV}_{1}$, which could be due to increased ventilation inhomogeneity in newly ventilated lung regions following inhaled antibiotic therapy (eg. by reduced air-trapping) $[24,28]$. However, it is important to note that the small evaluable sample size of the present study makes it challenging to draw clear conclusions.

In addition, chest physiotherapy to remove sticky mucus from the airways, prior to lung function testing may also lead to heterogeneity in LCI response. The inherent ventilation inhomogeneity combined with the clearance of mucus plugged airways (after chest physiotherapy) which were previously poorly ventilated (at baseline) leads to an increased LCI [29]. Indeed, a mean reduction of 0.2 in LCI response $30 \mathrm{~min}$ after physiotherapy was observed in CF patients with lung disease of varying severity, suggesting unpredictability of shortterm physiotherapy on LCI responses [30]. Similar to previously reported studies, the standard physiotherapy performed in the present study is strongly dependent on the therapist's discretion as well as on the daily performance and adherence of the individual CF patient. Although chest physiotherapy is typically performed before inhalation and is done at least $1 \mathrm{~h}$ prior to $\mathrm{MBW}$, there is no guidance on the timing for the physiotherapy at each visit. Hence, chest physiotherapy could have affected the outcome of lung function testing in this study to a certain degree. A detailed documentation of the timing and type of physiotherapy relative to $\mathrm{MBW}$ lung function testing in future clinical trials using LCI as a study endpoint is therefore recommended [29].

Based on the results from the present study as well as from available literature, it can be hypothesized that LCI can be an appropriate endpoint for efficacy trials in CF patients if the heterogeneity in lung function is limited by enrolling younger patients or patients with more milder lung disease and thus, limited ventilation inhomogeneities. Furthermore, including younger patients with milder lung disease and specifically defined time points for chest physiotherapy; while excluding false negative changes in lung function outcomes resulting from physiotherapy is recommended.

During the study period six AEs were reported, all of which were mild and moderate in severity, which is in line with previously published phase III data $[31,32]$ and the clinical experience with inhaled tobramycin.

A major limitation of the present study is the small sample size because of difficulties with patient enrollment and recruitment. The standard of care changed during the setup of the study, i.e., the majority of $P$. aeruginosa positive CF patients were to be treated with continuous inhaled sequential antibiotic combinations [33]. Hence, enrollment of patients on monotherapy was a challenge and thus, the study could include only $17 \mathrm{pa}-$ tients versus 35 patients that were planned to be 
enrolled. This was the primary reason for the premature termination of the study. Furthermore, it is important to consider the differences in the reference values of upper limit of normal of LCI while enrolling patients belonging to different age groups, for accurate interpretation of results.

\section{Conclusions}

In summary, the changes in $\mathrm{LCI}, \mathrm{FEV}_{1}$ and CFU were statistically non-significant at week 1,4 and 8 when compared with baseline which may be due to the heterogeneity in LCI response to antibiotic treatment and the low evaluable sample size.

Even if LCI is not identified as the ideal clinical efficacy endpoint for studies with antibiotic treatment (either intravenous or inhaled), it does not jeopardize the overall value of LCI as a more sensitive lung function parameter for $\mathrm{CF}$ patients with mild to moderate lung disease. Considering previously published data, LCI seems to be a suitable endpoint for drugs affecting the mucociliary clearance and to assess disease progression in cystic fibrosis. However, LCI alone does not seem to be the ideal clinical endpoint for efficacy studies with antibiotic treatment (either intravenous or inhaled) in small groups of CF patients.

\section{Supplementary information}

Supplementary information accompanies this paper at https://doi.org/10. 1186/s12890-020-01201-y.

Additional file 1: Supplementary Table 1. List of Independent Ethics Committees or Institutional Review Boards.

\section{Abbreviations}

AE: Adverse events; ANOVA: Analysis of variance; BID: Twice daily; BMI: Body mass index; CF: Cystic fibrosis; CFTR: Cystic fibrosis transmembrane conductance regulator; CFU: Colony forming unit; $\mathrm{Cl}$ : Confidence intervals; d: Difference; FEV 1 : Forced expiratory volume in one second; IVA: Ivacaftor; LCl: Lung clearance index; LS: Least squares; LUM: Lumacaftor; MBW: Multiple breath washout; $P$. aeruginosa: Pseudomonas aeruginosa; $\mathrm{ppFEV}_{1}$ : Percent predicted $\mathrm{FEV}_{\mathrm{l}}$; SD: Standard deviation; TIP: Tobramycin inhalation powder; TIS: Tobramycin inhalation solution

\section{Acknowledgements}

The authors thank Nihal Maremanda and Lakshmi Deepa (Novartis Healthcare Private Ltd., Hyderabad, India) for medical writing support and Mirjam Stahl, Division of Pediatric Pulmonology and Allergy and Cystic Fibrosis Center, Department of Pediatrics, University of Heidelberg, Germany, for discussion of the LCl data.

\section{Authors' contributions}

All authors assume responsibility for the accuracy of the data interpretation and approved the manuscript for publication. UM, CS, and JZ contributed to study conception, protocol development, data analysis and interpretation of data. SN and UM contributed on the interpretation of data and critical review of the study, SS and JZ drafted the first version of the manuscript. All authors helped with the review and finalization of the manuscript.

\section{Funding}

The funding for study design, data collection, analysis, and interpretation was provided by Novartis Pharma GmbH. Medical writing support for the manuscript, in accordance with Good Publication Practice (GPP3) guidelines (http://www.ismpp.org/gpp3) was funded by Novartis Healthcare Pvt. Ltd., Hyderabad, India.

\section{Availability of data and materials}

The data generated during and/or analyzed during the current study are available from the corresponding author upon reasonable request.

Ethics approval and consent to participate

The study design was approved by the independent ethics committee and institutional review boards (Supplementary material); and was in accordance with the Declaration of Helsinki. Informed consent was obtained from each patient (or from parents for children $<16$ years of age) in writing before randomization.

\section{Consent for publication}

Not applicable.

\section{Competing interests}

SS has served as an investigator in clinical trials for Galapagos, Proteostasis, Celtaxsys, Flatley, Novartis Pharma GmbH and Vertex Pharmaceuticals Incorporated and has consulted for Teva $\mathrm{GmbH}$, Novartis Pharma GmbH, Chiesi GmbH and Vertex Pharmaceuticals Incorporated. SN and UM have nothing to disclose. CS and JZ are employees of Novartis Pharma GmbH.

\section{Author details}

'Division for Cystic Fibrosis, Department of Pulmonary Medicine, University Medicine Essen - Ruhrlandklinik, Essen, Germany. ${ }^{2}$ Cystic Fibrosis Center for Adults, University Hospital Munich, Med. Klinik V, Munich, Germany. ${ }^{3}$ Pediatric Pulmonology and Sleep Medicine, Children's Hospital, University of Duisburg-Essen, Essen, Germany. ${ }^{4}$ Novartis Pharma GmbH, Nürnberg, Germany.

Received: 22 August 2019 Accepted: 28 May 2020

Published online: 12 June 2020

\section{References}

1. Riordan JR, Rommens JM, Kerem B, Alon N, et al. Identification of the cystic fibrosis gene: cloning and characterization of complementary DNA. Science. 1989;245:1066-73.

2. Elborn JS. Cystic fibrosis. Lancet. 2016;388:2519-31.

3. Langton Hewer SC, Smyth AR. Antibiotic strategies for eradicating Pseudomonas aeruginosa in people with cystic fibrosis. Cochrane Database Syst Rev. 2017;4:CD004197.

4. Smith S, Rowbotham NJ, Regan KH. Inhaled anti-pseudomonal antibiotics for long-term therapy in cystic fibrosis. Cochrane Database Syst Rev. 2018;3: CD001021.

5. Stanojevic S, Ratjen F. Physiologic endpoints for clinical studies for cystic fibrosis. J Cyst Fibros. 2016:15:416-23.

6. Pittman JE, Davis SD. Decline in forced expiratory volume in 1 second in cystic fibrosis-watch the pendulum swing. J Pediatr. 2016;169:7-9.

7. Konstan MW, McKone EF, Moss RB, Marigowda G, et al. Assessment of safety and efficacy of long-term treatment with combination lumacaftor and ivacaftor therapy in patients with cystic fibrosis homozygous for the F508del-CFTR mutation (PROGRESS): a phase 3, extension study. Lancet Respir Med. 2017:5:107-18.

8. Sawicki GS, McKone EF, Pasta DJ, Millar SJ, et al. Sustained benefit from ivacaftor demonstrated by combining clinical trial and cystic fibrosis patient registry data. Am J Respir Crit Care Med. 2015;192:836-42.

9. Mott LS, Park J, Murray $C P$, Gangell $C L$, et al. Progression of early structural lung disease in young children with cystic fibrosis assessed using $C T$. Thorax. 2012;67:509-16.

10. Breuer O, Caudri D, Stick S, Turkovic L. Predicting disease progression in cystic fibrosis. Expert Rev Respir Med. 2018;12:905-17.

11. Judge EP, Dodd JD, Masterson JB, Gallagher CG. Pulmonary abnormalities on high-resolution $C T$ demonstrate more rapid decline than FEV1 in adults with cystic fibrosis. Chest. 2006;130:1424-32.

12. Subbarao P, Milla C, Aurora P, Davies JC, et al. Multiple-breath washout as a lung function test in cystic fibrosis. A Cystic Fibrosis Foundation workshop report. Ann Am Thorac Soc. 2015;12:932-9.

13. Kent $L$, Reix $P$, Innes JA, Zielen $S$, et al. Lung clearance index: evidence for use in clinical trials in cystic fibrosis. J Cyst Fibros. 2014;13:123-38. 
14. Horsley AR, Gustafsson PM, Macleod KA, Saunders C, et al. Lung clearance index is a sensitive, repeatable and practical measure of airways disease in adults with cystic fibrosis. Thorax. 2008;63:135-40.

15. Ratjen F, Hug C, Marigowda G, Tian S, et al. Efficacy and safety of lumacaftor and ivacaftor in patients aged 6-11 years with cystic fibrosis homozygous for F508del-CFTR: a randomised, placebo-controlled phase 3 trial. Lancet Respir Med 2017;5:557-567. Epub 2017 Jun 9.

16. Green $\mathrm{K}$, Kongstad T, Skov M, Buchvald F, et al. Variability of monthly nitrogen multiple-breath washout during one year in children with cystic fibrosis. J Cyst Fibros. 2018;17(2):242-8.

17. Houltz B, Green K, Lindblad A, Singer F, et al. Tidal N2 washout ventilation inhomogeneity indices in a reference population aged 7-70 years. Eur Respir J. 2012;40:P3797.

18. Tiddens HA, Bos AC, Mouton JW, Devadason S, et al. Inhaled antibiotics: dry or wet? Eur Respir J. 2014:44(5):1308-18.

19. Davies JC, Sheridan H, Lee P-S, Song T, et al. Effect of ivacaftor on lung function in subjects with CF who have the G551DCFTR mutation and mild lung disease: a comparison of lung clearance index (LCl) vs. spirometry. J Cyst Fibros. 2012;11(Suppl. 1):S15.

20. Davies J, Sheridan H, Bell N, Cunningham S, et al. Assessment of clinical response to ivacaftor with lung clearance index in cystic fibrosis patients with a G551DCFTR mutation and preserved spirometry: a randomised controlled trial. Lancet Respir Med. 2013;1:630-8.

21. Svedberg M, Gustafsson PM, Robinson PD, Rosberg M, et al. Variability of lung clearance index in clinically stable cystic fibrosis lung disease in school age children. J Cyst Fibros. 2018;17:236-41.

22. Ellemunter H, Eder J, Fuchs S, Gappa M, et al. Long-term improvement of lung clearance index in patients with mild cystic fibrosis lung disease: does hypertonic saline play a role? J Cyst Fibros. 2016 Jan;15(1):123-6.

23. Welsh L, Nesci C, Tran H, Tomai M, et al. Lung clearance index during hospital admission in school-age children with cystic fibrosis. J Cyst Fibros. 2014;13:687-91.

24. Yammine S, Bigler A, Casaulta C, Singer F, et al. Reasons for heterogeneous change in $\mathrm{LCl}$ in children with cystic fibrosis after antibiotic treatment. Thorax. 2014;69:183.

25. Sonneveld N, Stanojevic S, Amin R, Aurora P, et al. Lung clearance index in cystic fibrosis subjects treated for pulmonary exacerbations. Eur Respir J. 2015;46:1055-64

26. Hatziagorou E, Avramidou V, Kirvassilis F, Tsanakas J. Use of lung clearance index to assess the response to intravenous treatment in cystic fibrosis. Hippokratia. 2015;19:47-52.

27. VanDevanter DR, Ballmann M, Flume PA. Applying clinical outcome variables to appropriate aerosolized antibiotics for the treatment of patients with cystic fibrosis. Respir Med. 2011;105:S18-23.

28. Robinson PD, Goldman MD, Gustafsson PM. Inert gas washout: theoretical background and clinical utility in respiratory disease. Respiration. 2009;78: 339-55.

29. Grosse-Onnebrink J, Mellies U, Olivier M, Werner C, et al. Chest physiotherapy can affect the lung clearance index in cystic fibrosis patients. Pediatr Pulmonol. 2017;52:625-31.

30. Pfleger A, Steinbacher M, Schwantzer G, Weinhandl E, et al. Short-term effects of physiotherapy on ventilation inhomogeneity in cystic fibrosis patients with a wide range of lung disease severity. J Cyst Fibros. 2015;14: 627-31.

31. Ramsey BW, Pepe MS, Quan JM, Otto KL, et al. Intermittent administration of inhaled tobramycin in patients with cystic fibrosis. Cystic fibrosis inhaled tobramycin study group. N Engl J Med. 1999;340:23-30

32. Konstan MW, Flume PA, Kappler M, Chiron R, et al. Safety, efficacy and convenience of tobramycin inhalation powder in cystic fibrosis patients: the EAGER trial. J Cyst Fibros. 2011;10:54-61.

33. Dasenbrook EC, Konstan MW, VanDevanter DR. Association between the introduction of a new cystic fibrosis inhaled antibiotic class and change in prevalence of patients receiving multiple inhaled antibiotic classes. J Cyst Fibros. 2015;14:370-5.

\section{Publisher's Note}

Springer Nature remains neutral with regard to jurisdictional claims in published maps and institutional affiliations.

Ready to submit your research? Choose BMC and benefit from:

- fast, convenient online submission

- thorough peer review by experienced researchers in your field

- rapid publication on acceptance

- support for research data, including large and complex data types

- gold Open Access which fosters wider collaboration and increased citations

- maximum visibility for your research: over $100 \mathrm{M}$ website views per year

At BMC, research is always in progress.

Learn more biomedcentral.com/submissions 